\title{
Investigating effectiveness of in-service training courses: applications for in-service training of Tehran Municipality
}

\author{
Ali Ghavidel ${ }^{1}$, Dr. Mohammad Safari ${ }^{2}$ \\ ${ }^{1} \mathrm{MSc}$ in Human Resources Management, Alborz College, University of Tehran \\ ${ }^{2} \mathrm{PhD}$ in Management and Lecture at Faculty of Management, University of Tehran \\ E-mail address: m.safari@alumni.ut.ac.ir
}

Keywords: in-service training, human resources, efficiency, effectiveness, Tehran Municipality.

\begin{abstract}
Making a responsive, favorable and efficient official system can be realized thorough training courses based on its current and future needs. The main aim of organizational trainings is facilitating organizations staff improvement in all aspects. On the other hand, what makes planning and administering organizational trainings legal, is their efficiency degrees. Since, the constant improvement of training system is a vital necessity in advancing organizational goals, this study tries to examine components affecting efficiency and effectiveness of in-service training in organizations. The results can be applied by authorities of short-term training courses of Tehran Municipality Organization. Outcomes of the present study revealed that some components like training need assessment and adjusting education system with organization strategies have key roles in improving efficiency and effectiveness of in-service training courses in organizations.
\end{abstract}

\section{INTRODUCTION}

\section{Study question}

Self-efficiency of each country depends on development of that country on various fields and this, in turn, depends on the country activities. In fact, skillful human resources is one of the main and undeniable factors influencing social and economic development of each country (Mohammadi nayini, 2207:140). Organizations are made of several important factors including investment, human resources, and management. Many experts of human resources filed believe that organization efficiency depends on proper performance of these resources. Since human sources constitute a great part of organizations sources, meeting this their needs require regular and ongoing training activities in all organizational levels. Therefore, nurturing skillful staff, called development of human resources management, is an inevitable necessity that organizations intensely need it for survival and progress in this current ever-changing world (Matani et al, 2008: 48).

Given the fact that no organization can be assumed needless of in-service training of its staff, organizations hold in-service training courses in order to meet their needs for skillful and experts staff, improving conceptual, technological and human skills, as well as promoting and reaching their goals. In addition, examining the effectiveness of organizational in-service trainings helps planners and executives to gain a clear image of these programs. So, this study tries to examine those components that may have a key role in efficiency and effectiveness of short-term in-service training courses of organizations.

\section{Study Aims}

In-service training and improving human resources has a special role in all organizations. So, ' inservice training of organization staff have a key role in staff's efficiency promotion" (Rezayi, 2004:81). Since the aim of in-service training is to expand scientific abilities and expertise of organization staff in various levels, the current study follows these aims:

a) Examining components affecting efficiency and effectiveness of in-service training in organizations. 
b) Suggesting proper strategies for improving efficiency and effectiveness of in-service training in order to improve knowledge and skills of human sources of Tehran Municipality.

\section{Study importance and necessity}

Training is the most efficient and strongest process for transforming knowledge and skills to human resources and enforcing their abilities for observing their duties. Given daily changes, science and technology progress and job plurality, in-service training is necessary to prevent resources waste; and its administration needs planning and careful examination based on in-service training needs of the organization staff (Talebi, 2006). In other words, "staff in-service training is one of the most important factors for improving structure and activities of each organization" (Shahani, 1998).

So, because holding training programs in and organization can meet its need for expert staff in future, and it may be a guaranty for reaching organization strategic goals, each year, and many organizations hold training courses in an expansive range. Aims of such organizations include promoting human resources' abilities, and making a favorable and responsive official system through organization training. However, the main concern about the degree of efficiency of these training courses on improvement of level of staff's job skills to help organizations reach their determined goals, shows the importance and necessity of the present study.

\section{STUDY THEORETICAL BASIC}

\section{Definitions and Concepts}

a) Training: training in an organization means planned and continuous attempt of the organization to improve staff's efficiency levels and the organization performance. In other words, "improving staff's skills and knowledge in order to improve organizational and individual performance, as well as, promoting organization chance to reach its goals" (Kasiri nezhad, 2005: 140).

b) In-service training: in-service training include holding various courses of internship, retraining, knowledge promotion, and educational conferences with the aim of improving knowledge and using other recruitment and financial benefits (Safi, 2004:163).

c) Efficiency: efficiency means maximum usage against spent costs for efficiency, individuals and organization try to properly do their duties, meaning that efficiency has a close relationship with the process control and resources application in the process administration period (Baqi nasrabadi, 2010: 37).

d) Effectiveness: means the degree of reaching organizational determined goals (Najaf beige, 2006: 102).

\section{Perspectives of some experts on organizational training}

Change is the most important feature that organizations as main pillars of the society confront with. An organizational perspective, change means alteration and evaluation in an organization in order to providing it an opportunity for its survival and continuous activities regarding its environmental situations. The main or early feature of such situations is their complexity, variety, and fast evolution. In these conditions, most of the organizations seek a resolution for this problem. A resolution suggested by most of the experts is training and improving human resources (Pubstaft, 1995: 5).

a) Davis Velipite: he believes that training is a process through which the individual acquires or improves necessary skills for doing a task or a professional duty. Then, training process provides individuals with an opportunity for realizing learning experiences and hence, staff can perform their current and future professional duties with more efficiency (Bartarm, 2006: 132).

b) Nickolas: this author maintains that training structure for staff empowering has 3 stages: 
First stage: Analyzing staff's current abilities and helping them to maximize their talents.

Second stage: using training techniques by managers to use staff which is higher than their current abilities.

Third stage: access to staff maintenance via sharing ideas and value (Orooei, 2002:35).

c) William Eich Dropper: he asserts that development basis of a society relays on training since development and training of human resources is the first factor affecting countries developments and is considered by managers as a significant program (Abtahi, 2006: 60).

d) Radion: this scholar declares that the best way for a comprehensive evaluation is using a systematic approaches. He concludes that the best way for assessing a training program is to measures changes occurring in participants' skills and efficiency after training sessions, and their abilities to apply their learnings in the real environment (Bartem and Gibson, 2006: $10)$.

e) Thomson: Thomson (1990) defines in-service training a process that improves quality and quantity of staff's efficiency and effectiveness development, as well as a factor for improving staff's professional satisfactions and spiritualties (Parsa and Qanbari, 2009:90).

\section{FINDINGS AND DISCUSSION}

\section{Components affecting efficiency and effectiveness of in-service training}

\section{a) Training need assessment}

Need assessment is a process that tries to resolve present defects. It is an attempt for determining needs; and finally need assessment is an activity that measure distances and inefficiency (Royse, Staton-Tindall, Badger and Webster. 2009: 3).

Witkin (1994) opines that need assessment may be used in the internal level of a system with the aim of gathering main data. For instance, in local institutions, need assessment can be focused on learners', educators' and other staff's needs. He has determined 3 levels for need assessment including:

\section{First level: receiving services}

Second level: offering services

\section{Third level: resources and resolutions}

Source: need assessment levels of Witkin

Need assessment is a main principle in all training systems that its foundation depends on planned alterations to make favorable behavioral changes in participants via training programs. One of the main reason explaining the necessity of need assessment is to gain sure that the most proper training methods, content, as well as levels of teaching has been selected (Suanson et al, 1997; quoted by Saburi and Ammani, 2010: 46).

In training realm, need assessment is considered as a necessary component of planning process. This component due to its underlying role has a higher level of importance and sensitivity compared to other parts of training process, and if done correctly, it will provide a more objective basis for this process (Pakdel, 2000: 65). The destination of need assessment is accessing to information about main and applicable duties for performing job role, knowledge, skills and attitudes required by those duties. Hence, it can be said that need assessment is an information gathering tool that if performed correctly, takes organizations from a passive and obscure position out, and puts them a in a transparent and metareaction one, and obtains information about implicit and explicit needs of organizations that will be met by planned organizational programs (Barbazette, 2006: 5). It should be mentioned that what matters in a training need assessment is re-defining the training need concept. 
Training needs assessment is one of the main trends of training system that is the major basis of planning, administration, and evaluation of its activities and determining its problems and weak points in training system is the other aim of training need assessment. In summary, the most substantial aims of need assessment are:

- Providing information for planning

- Evaluating programs: need assessment is the early evaluative process for executing future programs.

- Making training systems and institutes responsible

- Diagnosing or identifying weak points or main issues in organizations or systems

- Facilitating development of organizations and their staff

- Using resources and facilities in an optimized way (Mohammadi, 2006: 40).

From the necessity view, need assessment may be performed for one or a set of these reasons:

- need for performance improvement

- need for more thrift or cost control

- need for efficiency improvement, and

- need for improvement of offered services (Rezayi Jaffari, 2006).

\section{Main analyses in training need assessment}

There are three main analyses for identifying training needs including: organization analysis, individual analysis, and job analysis. In the next section, these analyses will be discussed on more details.

\section{Organization analysis}

Given many training experts' opinions, achieving goals of a business should be the final attention extreme in all kinds of attempts related to organizational development and training. Analysis and execution of organization needs have to be the first step in an effective need assessment (Jackson, 1996:306). Organization analysis include: organizational resources and goals analysis, change of the organization climate for training analysis of efficiency indexes like work resources cost, outputs (efficiency), quality of outputs, waste, facilities usage, maintenance, and evaluation of organization climate (Jackson, 1996: 306).

\section{Individual analysis}

Individual analysis helps training experts to identify staffs who needs training. In some conditions, like introducing a new technology or service, all staff may need training. However, it is not the case in other conditions. Individual analysis is defined as the investigation of distance between an individual's current competencies and necessary or favorable competencies for him/her and include the below mentioned stages:

- Determining whether functional deficits result from lack of knowledge, skills and abilities (a training issue) or comes from problems related to job design or motivational issues?

- Identifying those staff who needs training

- Determining staffs who are ready for training (...et al, 2003: 260). 


\section{Job analysis}

Job analysis, as the main basis for professional training, is the major step in designing training courses, training need assessment, and training teaching and evaluation. Till job analysis is not performed, training authorizers will not have a transparent awareness about what they are going to plan for. Job analysis is the process of describing and recording information about affairs and activities related to a profession. Information described and recorded in this process include a job aims, the gravest duties of activities of a job operator, and conditions that the job performs in (Jackson, 1996: 167).

Accordingly, the above mentioned studies reveal that recognition of staff's training needs is the basic necessity in planning for various training courses and these needs are under the influence of three major factors including organization, individual, and job. Performing theses analyses is based on a total-to-part approach that the analysis process in it starts with organization analysis. In the next step, individual is analyzed. Each individual has his/her own exclusive personality structure that makes him/her different from others; recognition of each individual's needs facilitates his/her adoption with a job. Finally, in job analysis a list of training needs for each job is provided. However, in performing this analysis, two important points should be attended.

a) Using accurate tools with proper validity and reliability

b) Maintaining this process. If we accept that change is a main principle in organization environment, and also accept that acceleration has intensively increased in the current century, we will more notice the importance of this point. In these ever changing situations, these analyses will have no benefit, unless they be performed regularly.

So, one of the factor assuring effectiveness of organizational training is a scientific, comprehensive and real needs assessment, and through this, "potential capacities of staff and, in turn, the organization sublimity becomes possible".

\section{c) Managerial supports}

Success of training programs depends on comprehensive supports of organization managers. If managers accept this as a belief and value, and require other related organizations to support them, too, quality of administration of training programs may highly improve. Hereupon, managerial support means that necessary opportunities be provided for all managers and experts and training programs enjoy all-dimensional organizational support. Scientific validity and admissibility of educators, cooperative teaching-learning approaches, proper time and place for holding courses, not imposing personal (mandatory and non-scientific) costs for participating in training courses, and serious tendency to make enough initiative in contents are among the sings of successful and beneficial management of training courses (Parsa and Qnabari Homaykooh, 2009: 107). So, training in organization will be productive if managers try to turn organizations into learning ones. To put it differently, managers should provide staff with conditions that motive them to learn both form the outside and inside the organization.

\section{d) Training content}

Training content includes "knowledge, skills and attitudes selected and organized via learning experiences and offered to learners" (Farmahini farahani, 2008: 106-105). Training work becomes successful if it has a suitable training content. Timeliness of training content and its adjustment with learners' needs to help achieving organizational goals are important factors affecting the success of training planning. Training content should be designed and codified carefully. The reason of naming the present century as "Information half-life century" is that every 5 years, half of the humans' information is abolished and replaced by new ones, and should be considered in training contents (Fathi vajrgah, 1994). 
Content of training courses requires a set of technical necessities. For instance, contents should

- include a proper pattern of pre-determined behavioral goals

- have subjective and imaginable goals

- be applicable

- be new and non-repetitious

- be completely adjusted with main, secondary and behavioral goals to facilitate achieving them

Hence, content of training programs and their quality is one of the major entries of training system, and in-service training courses cannot reach an acceptable level of efficiency and effectiveness unless their contents have highly technical quality.

\section{e) Financial and physical facilities}

Among factors affecting successful administration of training programs in organizations, having suitable and attractive place for teaching, prediction necessary budgets, and avoiding strict and lackof-motivation programs can be mentioned. Therefore, it is necessary to provide learners with a proper learning environment via artistic approaches and using scientific data, as well as encouraging their motivation to learn (Kasiri nezhad, 2005: 149). So, buildings, facilities and equipment of training centers should have acquired quality for training goals. Hence, it is vital to determine a framework for necessary standards of financial and physical resources.

Competency is one of the standards in financial and physical realm. This principle emphasizes providing staff with proper training spaces, facilities, as well as, professional libraries in both physical and electronic forms, based on their numbers

\section{f) Teaching-learning approaches}

Necessity of attending to selecting the most suitable approach in teaching-learning process is one of the important issues in staff training system in organizations. Avoiding inefficient traditional method, not relying on superficial memorizing material, and attending thought and logic of learners is one of the concern of education and training experts. Therefore, to select the proper methods, age condition, development stages, environmental conditions, talents, abilities should be considered and based on evaluation of these factors, the most proper method should be selected (Kasiri nezhad, 2005: 150).

In teaching-learning filed, selected educators should be qualified in instructing in-service training materials, with an acceptable level of technical criteria and scientific degrees. In this filed, educators should use organized explorative learning method, which is between "guided learning" method and "explorative learning" method (in this method, basic skills and early knowledge is offered to learners through discovering learning). In addition, professors and educators have to improve their constant learning and self-learning in learners. On the other hand, educators should have a course design and determine training activities in training courses. In addition, they should determine and select various teaching methods and offer materials that are adjusted with the goals and contents of training courses. These educators should be able to use training-helping tools symmetric with courses content and training technology in teaching, and introduce new resources to learners. Therefore, the above mentioned points form a set of strategies in teaching-learning field that should be attended.

Some of the most important merits of adjusting training system with organization strategies include:

* Identifying training direction and acts as a guidance for training system

* Determining priorities and help planning and administrating new training designs

* Coordinating all decisions and training programs for facilitating achieving determined strategies in the whole organization

* Enabling training system to turn its passive state into an active and future-making state 
So, regarding the necessity of organizational training efficiency in determining the training output, promotion of training quality clearly appears. Considering these components in training structure may result in:

a) Adjustment of actioners' behavior with organizational role expectations

b) Changes in job behavior, meaning increase in knowledge and skill in job performance

c) Changes in Professional function, meaning improvement in profession real function

\section{RESULTS}

Organizational trainings have an important role in affairs improvement and they facilitate organization development through knowledge, attitudes and needed skills. Since holding a training program requires a heavy cost, awareness of efficiency of training courses and their outputs is vital for managers. In other words, what makes organizational training programs legitimate and gives it direction, is determining their efficiency degree. Trainings efficiency becomes apparent in solving staff's functional, behavioral and professional problems. Results of studies should that using efficient training in an organization require attending to influencing factors in training realm. These factor include training need assessment, training content, support if organization mangers, financial and physical facilities, teaching-learning strategies, and adjusting the training system with organization strategies. In general, a review on these components show that:

a) Efficient recognition and analysis of training needs is the pre-assumption of a successful training system, and determining training needs is the first factor inestablishment and insurance of training function efficiency. If these can be performed properly, provide a more objective basis for planning as the map of efficiency. In this condition, the probability of training program adjustment with organization, staff and professional needs increase and therefore, its efficiency may also improve.

b) Organizations cannot achieve their determined goals unless training content has a favorable level of quality. In addition, there should be scientific principles for the training program content. This has three reasons: first, it make training constant; second, training content should be related to current issues; and third, it provides an opportunity for learning multiple activities (those that uses various senses and increase learners' motivations and learning abilities). Also, selection of proper teaching strategies should be done before producing training materials.

c) Making adjustment between training system and total strategies of the organization, as well as analysis of environmental opportunities and treats play a key role in efficiency and effectiveness of training courses in order to facilitate achieving organizational qualifies goals.

Hence, the present study manifests that if organizations attend to components affecting efficiency and effectiveness of training courses, they result in:
a) Job knowledge improvement
b) Job skills improvement
c) Changes in job behavior and attitudes
d) Work precision improvement; and
e) Activities quality improvement

\section{SUGGESTIONS}

Given the obtained results, the authors suggest several points in order to improve efficiency and effectiveness of in-service training courses that try to amend knowledge and skills of human resources with the aim of facilitating achieving main training goals, or in other words, promoting efficiency system in organizations. 
a) Identifying real needs of organizations and prioritizing them

b) Designing purposeful and proper program to meet training needs

c) Performing the training process accurately and becoming sure of its realization in each stage (i.e, evaluation of training courses in its duration)

d) Providing new facilities and tools to have a qualified training course

e) Adjusting training content with organization, staff and job realms needs

f) Identifying organizational goals and adjusting staff training courses with organization macro strategies and missions

g) Selecting policies based on internal and external adjustment of organizational training system

h) Attending factors that can change in staff's behaviors, including:

-Needed condition for staff training

- Organizational spaces which are effective in changing staff's behaviors

- Investing in training to make training courses more efficiency and effectiveness

i) Using re-engineering process of training (in two micro and macro levels) in organizational training system.

\section{References}

[1] Aghaie, M.; Vahedi, E.; Asadollahi, A. and Safari-Kahreh, M. (2014). An empirical investigating to effects of services marketing mix on brand dimensions in order to enhance brand equity in the Tehran's Chain Stores. Research Journal of Recent Sciences, 3 (2), 43-60.

[2] Arthor, Cohen; and Florence, Brower. (1972). Confronting Identity: The Community Collebe Instructor ,Engelwood Cliffs $\mathrm{Nj}$, Printice hall.

[3] Baqi nasrabadi, Ali, Shadelouyi, Nooriye. (2010). The role of human resources in organizational efficiency, Hosun Journal, No.26, P. 35-43.

[4] Barbazette, Jean. (2006). Training Need Assessment, Published by Pfeiffer

[5] Bartram, Shron. (2006). Need assessment of staff professional training, translated by: Zohre Khoshneshin, Training center of Resources Minstry maantgers press.

[6] Fati vajegah, Koorosh. (1994). Familiarity with staff's in-service training, General Office of In-service training Press.

[7] Goldstein, Irwin L. (1993). Training in Organization, Brook/Cole Publishing Company, 3rd edition, California.

[8] Jackson Susan E. (1996). Human Resource Management, West \& .Schuler Randall S. Publishing Company

[9] Kasiri nezhad, Naqi (2005), Functions of training in organizations, Educators Journal, No. 18, p. 139-152.

[10] Metani, Mehrdad, Hassan zade, Ramezan, Metani, Mojtaba. (2008). Investigation of inservice training curses effectiveness in developement of human resources, Researcher Journal, No. 11, P. 48-56.

[11] Mohammadi nayini, Mozhgan. (2007). Investigation of the effects of in-service training courses on staff's performances in official organizations in Arak city, Journal of Training Research, No. 10, P. 139-160.

[12] Mohammadi, Teimoor. (2006). Concept and necessity of training need assessment, Journal of Reform and Training, No. 57 \& 58, P. 38-41.

[13] Najaf beige, Reza. (2006). Organization and management, Tehran, Research Ministry of Islamic Azad University. 
[14] Noohi, Esmat (2008). Identifying training needs, Pak: scientific, cultural and social Journal, No. 17.

[15] Pakdel, Rahmat Allah (2000). Need assessment in systematic training process, Tadbir Journal, No. 102

[16] Parsa, Abdollah, Qnabari homaykooh, Amir (2009), Investigating beneficial level of inservice training programs and its relation with knowledge and job skills improvement in Shahid Chamran University of Ahvaz, Education and Training Journal, No.5, Vol. 16 (1), p. 88-112.

[17] Pubstaft. (1999). A model for research on training effectiveness.

[18] Qadirian, Abbasi Ali (2003), Economy and Knowledge: Patterns of organization leadership and new training necessities, Journal of Research and Planning in supreme education, No. 31 $\& 32$.

[19] Rezayi Jfari, Alireza. (2006). Need, Baqiyat-Allah Medical Sciences University, Epic Medicine Research Center.

[20] Rezayi, Akbar. (2004). investigation of the effect of in-service training courses on job performance, Bime Journal, No. 19, Vol. 76, P. 81-100.

[21] Royse, D., Staton-Tindall, M., Badger, K., Webster, M. (2009). Need assessment. Published by Oxford University Press, Inc. New York.

[22] Saboori, Mohammad Sadeq and Ammani, Ahmad Reza (2010), Factor analysis of training needs of cotton-planter from experts' perspectives in Agriculture Organization of Semnan province. Journal of Agriculture Cultivation and Training, p. 45-56.

[23] Safari, M. (2015). Customer Lifetime Value to managing marketing strategies in the financial services. International Letters of Social and Humanistic Sciences, 1 (2), 164-173.

[24] Safari-Kahreh, M. \& Safari-Kahreh, Z. (2012). An Empirical Analysis to Design Enhanced Customer Lifetime Value Based on Customer Loyalty: Evidences from Iranian Banking Sector. Iranian Journal of Management Studies, 5(2), 145-167.

[25] Safi, Ahmad. (2004). Organization and principles of Education System in Iran, SAMT press.

[26] Shahani, Asad. (1998). Evolution of in-service training courses from staff's perspectives of Agriculture Organization of Mazandaran province in years 1995-97. M.A Thesis, Tarbiyat Modarres University

[27] Tlebi, Hooshang (2006), Analyzing usage degree and effects of various kinds of training and staff's knowledge and skills promotion.

[28] Witkin, B. R. (1994). Needs Assessment since 1981. The State of the Practice, 1 (1), 17-27. 